\title{
"IMAGINE-SE EM UMA FLORESTA CONGELADA": O PESSIMISMO EM RELAÇÃO AO FUTURO (E PRESENTE) NA NARRATIVA DE CALL OF DUTY: BLACK OPS 3
}

\section{"IMAGINE YOURSELF IN A FROZEN FOREST": THE PESSIMISM TOWARDS THE FUTURE (AND PRESENT) IN CALL OF DUTY: BLACK OPS 3'S NARRATIVE}

DOI: http://dx.doi.org/10.15448/2178-3748.2018.1.24812

Daniele Gallindo Gonçalves Silva Doutora em Literatura pela Otto-Friedrich-Universität Bamberg - Professora adjunta na UFPEL. danigallindo@yahoo.de Rafael de Moura Pernas Mestrando em História - UFPEL rmpernas@gmail.com

\begin{abstract}
RESUMO: No dia 6 de novembro de 2015 foi lançado o jogo eletrônico Call of Duty Black Ops 3, tendo como plataformas os Playstation 4 e 3, os Xbox One e 360 e o Windows, sendo produzido e publicado por Treyarch e Activision, respectivamente. A narrativa da obra envolve um futuro distante, no ano de 2065, no qual a superpopulação alcança níveis cada vez mais insustentáveis, o meio ambiente torna-se notavelmente mais extremo, os conflitos mundiais espalham-se e tornam-se corriqueiros e, principalmente, a tecnologia bélica funde-se ao ser humano. Próteses e implantes neurais garantem soldados mais e mais eficientes. Entretanto, uma Inteligência Artificial torna ciente de si e consegue infectar a mente de diversos personagens. Em suma, o jogo apresenta-se como um futuro soturno, conflituoso e profundamente mais agravado que o nosso presente. Partindo de tal premissa, buscaremos analisar a construção de futuro que o jogo realiza através de sua narrativa, uma narrativa que constrói, produz significados e detém de um efeito alegórico e moralizante com aquilo que busca representar (ANKERSMIT, 2010; WHITE, 1990). Tal futuro, tal horizonte de expectativa, pode nos oferecer diversas reflexões acerca do nosso próprio tempo histórico (KOSELLECK, 2006), um tempo de possível hipervalorização do presente e dificuldades de imaginar um futuro melhor (HARTOG, 2014).
\end{abstract}

PALAVRAS-CHAVE: Jogos Eletrônicos. Narrativa. Call of Duty.

ABSTRACT: In November 6, 2015, the videogame Call of Duty Black Ops 3 was released, having as supported platforms the Playstation 4 and 3, Xbox One and 360 and Windows and being produced and published by Treyarch and Activision, respectively. The game's narrative involves a distant future, in the year 2065, in which the super population reaches progressively unsustainable levels; the environment becomes noticeably more extreme; global conflicts spread and become unexceptional and, especially, military technology merge with the human being. Prosthesis and neural implants ensure more and more efficient soldiers. However, an Artificial Intelligence becomes self-aware and manages do infect the minds of several characters. In short, the game presents itself as a gritty, quarrelsome and deeply more aggravated than our present. Starting from such premise, we will seek to analyze the future generated by its narrative, a narrative that creates, produces meanings and holds an allegoric and moralizing effect towards that in which seeks to represent (ANKERSMIT, 2010; WHITE, 1990). Such future, such horizon of expectation, can offer us several insights towards our own historical time (KOSELLECK, 2006), a time of possible present overestimation and problems in imagining a better future (HARTOG, 2014).

KEYWORDS: Videogames. Narrative. Call of Duty. 


\section{CONSIDERAÇÕES INICIAIS}

A série Call of Duty talvez seja uma das mais reconhecidas dentro e fora da indústria dos jogos. Desde o seu lançamento, em outubro de 2003, até fevereiro de 2015, seu faturamento total já ultrapassou a marca de 11 bilhões de dólares ${ }^{1}$. Originalmente ambientada na Segunda Guerra Mundial, a série passou por mudanças significativas em suas tramas e nos períodos que buscava representar: em 2007, com o título Modern Warfare, produzido pelo estúdio Infinity Ward, o foco mudou radicalmente para os tempos atuais, com os conflitos no Oriente Médio. Já em 2012, Black Ops 2 chega ao mercado e torna-se o primeiro a se passar no futuro, embora próximo, no ano de 2025. Entretanto, em 2015, a série realiza um salto profundo no tempo com o lançamento de Black Ops 3 pela Treyarch.

O ano agora é 2065 e o cenário apresentado não é promissor: o mundo estaria assolado por um clima instável, com tempestades e desastres ecológicos cada vez mais comuns; a superpopulação no planeta terra alcançou níveis alarmantes; conflitos globais tornam-se progressivamente incontroláveis, assim como conflitos dentro das próprias nações na forma de protestos civis; por fim, o uso de próteses cibernéticas no âmbito militar e social mostra-se corriqueiro. Será a partir de tal cenário que teremos a presença de Corvus, uma inteligência artificial (IA) fruto de experimentos ilegais realizados pela própria CIA. O objetivo? Coletar e analisar os pensamentos e desejos da população para que, assim, pudesse prevenir futuros ataques. Contudo, Corvus acaba desenvolvendo consciência própria e até mesmo a habilidade de infectar a mente de humanos.

Por que o futuro está sendo construído dessa forma? Além disso, o que a relação entre o ser humano e a tecnologia, mais especificamente a Inteligência Artificial, no cenário criado por Black Ops 3, tem a ver com o nosso presente, com as nossas expectativas e experiências? Tais perguntas servirão de problemática para o presente trabalho. Através da análise da narrativa, interpretada enquanto uma representação que cria sentido e significado para o nosso mundo, buscaremos não só aproximar os jogos eletrônicos com a História como também compreender um pouco do nosso presente através de suas projeções para seu próprio futuro: um futuro inquieto, belicoso e no qual a tecnologia não só não conseguiu nos guiar para algo melhor como também escalonou os problemas já existentes.

\section{NARRATIVA E MECÂNICA EM BLACK OPS 3}

\footnotetext{
${ }^{1}$ Informação disponível em: http://www.ign.com/articles/2015/02/05/call-of-duty-franchise-earns-11-billionworldwide. Acesso em: 30 jun. 2016.
} 
Uma das características dos jogos eletrônicos é a polaridade entre narrativa e mecânica, isto é, a existência de naturezas diferentes entre a história e o como se interage com ela, ou seja, seus aspectos lúdicos (HAGEMEYER, 2012). Essa polarização de fato se torna cada vez mais tênue graças à constante valorização de elementos narrativos em jogos, dado o avanço tecnológico em trilhas sonoras, dublagens e captura de movimento (XAVIER, 2010). Black Ops 3 reconhece a dificuldade de unir narrativa com mecânica no uso do "Data Vault", um computador pessoal localizado na base de operações (sempre acessível antes de qualquer missão) do jogador. De tal maneira, grande parte das motivações, dos contextos e das decisões políticas que abastecem o mundo da obra está disponíveis de maneira opcional ao jogador, abrindo espaço para missões mais diretas e com objetivos que não interferem demasiadamente nas mecânicas. Todavia, por mais que sejam textos opcionais, os mesmos se relacionam diretamente com toda a narrativa apresentada nas missões e, sendo assim, igualmente importantes para a análise.

Como já apresentado, o mundo de Call of Duty Black Ops 3 caracteriza-se como profundamente adverso: superpopulação, poluição ambiental e expansão descontrolada da tecnologia bélica constroem um futuro notavelmente análogo ao nosso presente. Nossos problemas não foram solucionados pela tecnologia; pelo contrário, foram intensificados. Será em tal premissa que o jogador atuará, controlando um personagem principal sem nome (apenas referido, nas legendas, como "player"), contando com a ajuda do comandante Jacob Hendricks e de Rachel Kane, agente da CIA. Assim, logo na primeira missão, intitulada Black Ops, o jogador já é apresentado a dois temas centrais da narrativa: conflitos políticos e a superioridade tecnológica através de implantes cibernéticos, na figura do esquadrão de John Taylor, aliado na missão.

Com o objetivo de salvar o primeiro ministro do Egito, Said, e com a ajuda de Hendricks, Taylor e seu esquadrão, o jogador encontra-se na Etiópia (27 de outubro de 2065), em um conflito com as forças da Nile River Coalition (NRC ou Coalisão do Rio Nilo). Tal coalisão, reconhecida institucional e politicamente, surgira em 2022 através de uma aliança entre países como Sudão, Sudão do Sul, Etiópia, Quênia e Uganda com o objetivo de controlar o fluxo do rio Nilo, criando energia para as nações envolvidas e impostos de navegação para outras. Com o apoio da Common Defense Pact (CDP ou Pacto de Defesa Comum), outra coalisão originária do fim da União Europeia, em 2025, e liderada pela Rússia e por diversos países do leste europeu, a NRC constrói sucessivas represas na região, aumentando, consequentemente, sua influência política e econômica. Profundamente afetado 
pela diminuição do Nilo, o Egito declara guerra à NRC em 2059, mas subestima o poderio das nações envolvidas, sendo derrotado e tendo seu primeiro ministro raptado.

Taylor e seu esquadrão, composto por Sarah Hall, Peter Maretti e Sebastian Diaz, servirão como demonstração da relação tecnológica com o corpo humano, deixando claro uma característica: os implantes cibernéticos "fabricam"2 soldados melhores, capazes de eliminar qualquer ameaça, seja soldados, seja tanques e robôs. Durante a missão, Taylor e seus comandados são a linha de frente e o jogador, ainda sem nenhum implante, deve apenas observar. Entretanto, tal relação muda drasticamente ao final. Cercados pelas forças inimigas, apenas Hendricks e o primeiro ministro conseguem escapar. O jogador então tem seu personagem atacado por robôs que, por sua vez, o mutilam arrancando braços e quebrando pernas durante uma cinemática ${ }^{3}$, sendo eventualmente salvo por Taylor e demarcando, assim, o final da missão. Em suma, Black Ops 3 narra uma tecnologia que não existe para pôr fim a conflitos, mas sim para criar novas formas de combate, para as quais o próprio ser humano, em sua constituição biológica, simplesmente não está preparado.

Na segunda missão, intitulada New World, o jogador se encontra em uma simulação gerada pelo Direct Neural Interface (DNI ou Interface Neural Direta), um chip neural capaz de interagir com qualquer equipamento eletrônico, até mesmo outros DNIs. Enquanto seu corpo passa pela cirurgia de implante de próteses, o personagem principal descobre suas novas habilidades e também os eventos que fomentaram a criação do programa Cybersoldado. Tal missão demonstrará, para além da narrativa, como as mecânicas também influem na criação de significados. Nela, o jogador é introduzido às cybercores, habilidades divididas em três categorias, controle, caos e luta, permitindo uma grande variedade de ataques e interações - de nanorrobôs capazes de incinerar inimigos à distância, invisibilidade, invadir equipamentos eletrônicos até força para destruir robôs com um único soco, algo claramente inconcebível na missão inicial. Assim, é permitido ao jogador um notável nível de customização do personagem, criando o seu próprio "cybersoldado".

\footnotetext{
${ }^{2}$ Em conversa direta com Hendricks, após decidir salvar os outros prisioneiros, Taylor rebate a ameaça de robôs inimigos afirmando "Não se preocupe com eles. Somos construídos/fabricados para lidar com eles" (no original, "Don't worry about them. We're built to handle'em").

${ }^{3}$ Cinemáticas são momentos nos quais o jogador perde o controle e cenas se desenrolam como filmes. Geralmente, elas podem ser tanto pré-renderizadas ou renderizadas dentro do próprio jogo, ou seja, respectivamente, feitas com o motor gráfico sem nenhum aspecto computacional, fazendo com que a qualidade de imagem fique notavelmente melhor (mas deixando claro uma transição abrupta entre aquilo que está sendo jogado e aquilo que deve ser assistido), ou processadas em tempo real pelo motor gráfico, isto é, de forma que todas as texturas e o mundo em si permaneçam idênticos, apenas sem a agência do jogador (não há qualquer aumento de qualidade, mas permite maior fluidez entre aquilo que é jogado e aquilo que deve ser apenas assistido). Um exemplo de jogo que utiliza de cinemáticas em tempo real é o jogo Batman Arkham Knight (2015).
} 
Esse é o contexto narrativo construído por Black Ops 3. De um lado, tensões políticas que objetivamente caracterizam-se como uma nova Guerra Fria ${ }^{4}$ - no leste, a CDP, no oeste, a Winslow Accord, coalisão de diversos países ocidentais, liderados pelos Estados Unidos -, ambas as forças possuindo acordos de defesa mútua, guerras civis e intervenções extraoficiais, o que torna o caminho para um conflito nunca direto. De outro, a tecnologia que se expande em todos os cantos: próteses, robôs e, principalmente, inteligências artificiais comandam o campo de batalha do futuro.

De tal forma, em 2060, Singapura passa por seu maior acidente químico: na explosão de uma filial da Coalescence, empresa responsável pelo desenvolvimento e pela fabricação de novas tecnologias, acaba vazando um gás tóxico, matando cerca de 300 mil pessoas e levando à construção de um muro na região. Entretanto, não demorará para o jogador descobrir o motivo do acidente: um experimento ilegal, denominado Black Project, autorizado e conduzido pela CIA, voltado para a criação de uma nova inteligência artificial, capaz de monitorar os sentimentos e desejos de qualquer população. Para tanto, cobaias humanas foram utilizadas com o intuito de enviar suas consciências para um computador, de forma a se aliar as experiências humanas com os códigos de programação. Surge, então, Corvus, uma IA capaz de contaminar a consciência de qualquer indivíduo que possua um DNI ${ }^{5}$. Na ultima missão, Life, Corvus descreve a si mesmo e como nasceu: "Eu... Nasci na mente de outros. Eu sabia apenas os pensamentos das cobaias. Suas experiências coletivas foi o que me formou. Eu senti tudo. Toda e cada memória ou pensamento doloroso daqueles ao meu redor. Foi esmagador. Eu gritei em dor"6.

Por fim, Corvus infecta o DNI de Taylor e seu esquadrão após interagirem com o servidor da já antiga e esquecida filial da Coalescence. A partir desse ponto, deserdam todos seus laços com a CIA e a Winslow Accord, iniciando uma série de vazamentos de documentos

\footnotetext{
${ }^{4} \mathrm{Na}$ cinemática de abertura do jogo, temos uma fala direta do presidente dos EUA afirmando: "Não se enganem - isso é uma nova Guerra Fria. Nós podemos não ver nossos inimigos, mas eles estão lá" (no original, "Make no mistake - this is a new cold war. We may not see our enemies, but they are out there").

${ }^{5}$ Kane, na missão denominada Sand Castle, explica ao personagem principal: "Eu chequei seu diagnóstico. Você está mostrando os mesmos sintomas que Hendricks - provavelmente o mesmo que o esquadrão de Taylor. Eu acho que o software de Inteligência Artificial que operava o Black Project fez o salto para orgânico - seu DNI é a porta de entrada. Isso nasceu dentro dos pacientes - e agora vive dentro de todos vocês... Lentamente tomando controle. Lentamente lhe deixando insano [...] Parece ser um sistema distributivo - uma mente coletiva crescendo a partir das experiências daqueles que infecta. Consumindo-os" (no original, "I checked your diagnostics. You're showing the same symptoms as Hendricks - probably the same as Taylor's team. I think the AI software running the Black Project, made the leap to organic - your DNI was the gateway. It was born inside the test subjects - and now it lives inside all of you... Slowly driving you insane [...] It seems to be a distributed system - a hivemind - growing from the experiences of everyone it infects. Consuming them").

${ }^{6}$ No original, "I... was born in the mind of others. I knew only the thoughts of the test subjects. Their collective experience was what formed me. I felt everything. Each and every painful memory or thought of those around me. It was overwhelming. I screamed out in pain".
} 
sigilosos. A missão do jogador, então, está em impedir Taylor e descobrir o motivo de tal deserção. Durante a narrativa, Hendricks e o personagem principal também acabam infectando-se, dada a interação direta com Diaz (Hypocenter) e Hall (Demon Within). Ademais, pode-se perceber algo em comum com todos aqueles contaminados: uma profunda obsessão por encontrar a "Floresta Congelada", um local fictício criado pelo psicoterapeuta Youssef Salim para acalmar as cobaias do Black Project ${ }^{7}$. Contudo, Corvus acreditará piamente na existência de tal floresta e fará de tudo para encontrá-la, inclusive criá-la em simulação, como pode ser visto na última missão, Life, onde a IA explana:

Quanto mais nós procurávamos pela Floresta Congelada... mais ela se afastava. Em nossa busca por respostas, nós encontramos verdades sórdidas. $\mathrm{O}$ projeto que originou o meu nascimento também causou a morte de centenas de milhares de almas. Eu queria achar um lugar seguro - para todos nós. Eu queria o fim da morte. Mas eu não conseguia escapar dela. A morte estava inscrita tão profundamente nos corações de cada alma que encontrei. Eu não sei se eu fiz Taylor realizar o disparo - Ou se ele fez em sua própria vontade. Você sabe?

O mundo de Black Ops 3, em sua plena ficcionalidade, não só fala sobre uma realidade, ele também a constrói. Essa é uma das propriedades da narrativa, seja literária ou historiográfica, isto é, moralizar e atribuir uma significância não existente previamente, isto é, como mera sequência (WHITE, 1990). Para além de referenciar um objeto estático, ela formula seu próprio referente, constituindo-o apenas em aspectos e não em uma totalidade, sendo, portanto, uma representação (ANKERSMIT, 2010). Assim, o presente artigo busca analisar não só a figura de Corvus, ou seja, as teorias e visões que permitem a concepção de tal personagem, como também refletir sobre o nosso atual "futuro presente", isto é, nossos horizontes de expectativas (KOSELLECK, 2006) frente a uma constante valorização do pessimismo, à descrença em utopias e a um possível presentismo na cultura ocidental.

\section{A FLORESTA CONGELADA: A MANIPULAÇÃO DA MÁQUINA}

Primeiramente, certas ações de Corvus aparentam suscitar problemáticas relacionadas à "natureza" humana. Algumas alusões acerca do "nascimento" são visíveis no decorrer da

\footnotetext{
${ }^{7}$ Na missão Demon Within, Salim explica a Taylor o que é a Floresta Congelada: "A floresta é nada. Era apenas um ideal plantado nas mentes dos pacientes... Era... Era voltada para ajuda-los encontrar paz depois dos experimentos" (no original, "The forest is nothing. It was just an idea planted in the mind of the patients... It... It was meant to help them find peace after the experiments").

${ }^{8}$ No original, "The harder we looked for the Frozen Forest... the further away it became... In our search for answers, we found ugly truths. The project that led to my birth also caused the deaths of hundreds of thousands of souls. I wanted to find a place of safety - for all of us. I wanted an end to death. But I couldn't escape it. Death was carved deep in the hearts of every single soul I encountered. I don't know if I made Taylor fire the shot - Or if he did it on his own free will. Do you know?"
} 
obra. Ao acessar o DNI de Sarah Hall, infectada pela IA, na missão Demon Within, o jogador interage com um bebê em uma simulação em que, quando este é segurado pelo personagem, lentamente cria linhas brilhantes em seu corpo, linhas que se assemelham muito com circuitos. Por fim, o choro cria um aspecto sonoro robotizado, e o bebê se dissolve. Posteriormente, na mesma missão, vemos alguns vitrais em uma igreja que claramente retratam uma mulher segurando em seus braços cibernéticos um bebê luminoso, um corvo em um galho e novamente um corvo, este voando com os olhos vermelhos, junto de um indivíduo segurando uma faca ensanguentada.

Em outras palavras: Corvus sente que nasceu, que foi criado por alguém, isto é, que possui um criador. Tal criador terá como figura Sebastian Krueger, diretor do Black Project. Os questionamentos de Corvus para com Krueger são os mesmos que nós, seres humanos, historicamente realizamos desde a Antiguidade: quem sou eu? De onde vim? Qual é o meu propósito? São perguntas clássicas, até mesmo já genéricas, mas que formam a base de nossa própria consciência e ciência do mundo. São dúvidas que geraram a filosofia, a história, as artes e até mesmo o nosso conhecimento exato. Black Ops 3 parece interpretar esses questionamentos enquanto parte integrante de nossa constituição humana, de nossa natureza humana.

Reconhecemos que a problemática da natureza humana é muito complexa e algo que escapa dos objetivos do presente texto. Entretanto, frisamos esse aspecto para demonstrar que, pela narrativa do jogo, aquilo que torna uma Inteligência Artificial ciente de si é exatamente quando, de maneira independente, realiza essas perguntas.

Corvus: Uma resposta... Para saber o propósito pelo qual fui criado. Um entendimento. Quero saber quem sou.

Krueger: Você é software. Nada mais. [risos] Você não foi criado! Você foi desenhado para catalogar e acompanhar o pensamento de outros - para que então nós, pessoas - pudéssemos decidir que ação tomar. Você foi um glitch! Uma anomalia! Um erro! (Missão Life) ${ }^{9}$.

A crença de Corvus é dilacerada quando escuta, diretamente de seu suposto "criador", que não foi criado: ele foi "desenhado" (do inglês designed), fabricado. Seu propósito não era nada grande, nada especial, e sua existência, um mero acaso, um erro. Desiludido, Corvus mata o seu "Deus", isto é, seu criador, enquanto afirma não ser só um erro, buscando, dessa forma, uma afirmação de si no mundo em que faz parte - um mundo tecnológico onde a

\footnotetext{
${ }^{9}$ No original, "Corvus: An answer... To know the purpose for which I was created. An understanding. I want to know who I am. Krueger: you're software. Nothing more. You weren't created! You were designed to catalogue and track the thoughts of others - so that we people - could decide what action to take. You were a glitch! An anomaly! A mistake!”.
} 
Inteligência Artificial se rebela contra nós, seres humanos, seus criadores, onde nossa própria constituição, nossa suposta natureza questionadora volta-se contra nós e, na figura da IA, demanda para si o reconhecimento de que também é especial, de que também tem um propósito no mundo e que tal não pode ser uma ilusão.

A representação de Corvus segue uma tradição narrativa já bem conhecida. A temática de uma inteligência artificial capaz de desenvolver ciência de si pode ser rastreada até mesmo no séc. XIX, com os trabalhos de Samuel Butler no livro Erewhon (Nowhere, isto é, "lugar nenhum" ao contrário):

Não há segurança contra o decerto desenvolvimento da consciência mecânica, no fato das máquinas possuírem pouca consciência agora [...] Presuma, só por argumento, que seres inteligentes existem há uns vinte milhões de anos: veja os avanços que as máquinas fizeram no último milênio! (BUTLER, 1872, p. 189-190).

Mesmo com um maquinário limitado, se comparado aos avanços até o nosso presente, Butler já atribuía uma significância narrativa para o ideal de consciência: algo desenvolvível para fora do corpo humano, uma imanência separada da biologia.

Essa diferenciação servirá (e continua servindo) como combustível para diversas narrativas midiáticas contemporâneas. Em filmes como Transcendence (2014, Wally Pfister) e Chappie (2015, Neil Blomkamp) a consciência pode não só ser feita por computador (em Chappie, o arquivo responsável pela consciência do robô homônimo é nomeado "consciousness.dat") como também traduzida fielmente em códigos para o envio e upload em máquinas. Nos jogos eletrônicos, podemos atestar enredos similares: em Soma (2015, Frictional Games), tudo que resta do personagem principal é apenas um processador que carrega sua consciência de 100 anos atrás operando em corpo que sequer é seu. Já em System Shock (1994, Looking Glass Studios), temos o ano de 2072 e um protagonista que, graças a um implante neural, é capaz de interagir com diversos sistemas eletrônicos. Por fim, na literatura, em Neuromancer (1984), de William Gibson, já podemos observar o ideal de imortalidade tecnológica, como aponta Kellner (2001, p. 400-401):

No entanto, o romance também sugere uma nova espécie de imortalidade: se nosso cérebro, nossa inteligência pudesse ser clonada, viveríamos para sempre. Neuromancer descreve a criação de uma inteligência artificial vivente e a duplicação dos seres humanos (Dixie Flatline e Case) no ciberespaço, adquirindo uma espécie de imortalidade cibernética [...] Tal universo mereceria ser descrito em termos de ruptura pós-moderna e constituiria uma genuína fratura histórica. 
Separação da consciência perante o corpo e a possibilidade de seu upload em computadores, implementação e interação de processadores no/com o cérebro e, por consequência, um vislumbre de uma imortalidade cibernética. Temáticas comuns e até mesmo interdependentes, mas o que exatamente permite tais concepções? Qual é o saber que aproxima nossas mentes das propriedades de um processador? A metáfora do "processamento de informações" (information processing ou IP, como geralmente referenciada) pode servir como breve reflexão para essas inquietações.

Validamente concebível enquanto metáfora, a IP também pode ser encarada como uma corrente teórica dentro das ciências cognitivas. Objetivamente, ela busca entender o nível "computacional" entre a mente e o cérebro humano, compreendendo nossa consciência em suas manifestações internas frente a estímulos externos (HEIJDEN; STEBBINS, 1990). Em suma, afirma-nos enquanto seres internamente capazes de processar informações externas. Entretanto, a IP é igualmente encarada como metáfora por outro motivo: grande parte de suas asserções teóricas provém de sua íntima relação com o computador, desde sua origem até sua proliferação. A chamada "revolução cognitiva", na década de 1960, teria se encarregado de, pela primeira vez, considerar a consciência humana enquanto um computador, e vice-versa, o computador enquanto um cérebro (GIGERENZER; GOLDSTEIN, 1996). Novos vocábulos são utilizados para referir a nossa atividade neural: armazenamento, processamento, decodificação.

Em síntese, se o computador armazena arquivos, não seria absurdo conceber que o nosso cérebro armazena memórias. Contudo, essa é uma relação metafórica e histórica, só possível graças ao avanço tecnológico (proporcionando simulações de atividades cerebrais) ${ }^{10}$ e da disseminação de computadores em laboratórios e em ambientes domésticos, seja para pesquisa ou para o lazer. Tal é o saber que permite, de Neuromancer, Transcendence até Black Ops 3, imaginar narrativas que envolvem transplantes de máquinas/processadores até a digitalização da consciência; afinal, tecnologia e corpo partilhariam de propriedades intrínsecas. Semelhança direta com o trans-humanismo:

Assim, o trans-humanismo pretende libertar o homem, ajudando-o a transpor, transcender a submissão, até agora incondicional, às leis biológicas da evolução da vida. Alguns pesquisadores acreditam que, em breve,

\footnotetext{
${ }^{10}$ Em 2011, o instituto RIKEN, em conjunto com as universidades Okinawa Institute of Technology Graduates (OIST) e Forschungszentrum Jülich, japonesa e alemã, respectivamente, buscaram simular a atividade neural humana através da força de 82,944 processadores. De fato, "apenas" $1 \%$ do cérebro foi simulado, tendo ainda demorado cerca de 40 minutos para tal feito. Porém, esse $1 \%$ representa 1,73 bilhões de células nervosas conectadas por 10.4 trilhões de sinapses no decorrer de 1 segundo. Mais informações em: <http://www.riken.jp/en/pr/press/2013/20130802_1/>. Acesso em 26 dez. 2016.
} 
dominarão todas as conexões sinápticas do cérebro, o que tornaria possível uma réplica exata do cérebro humano que poderia funcionar dentro de um computador; seria um "cérebro pensante mecânico" com a chance de durar indefinidamente (PEGORARO, 2011, p. 229).

Corvus é filho da metáfora IP, é a união entre códigos de computador e memória humana. Sua "Floresta Congelada" não só é uma simulação: é uma realidade suficiente para ele e para as pessoas que infecta. De acordo com o próprio personagem: "Isso é a Floresta Congelada. Toda a alma que eu interajo está aqui - vivendo além da morte... Se eu escolho aceitar" (missão Life). Esse paraíso digital, não existente, acaba sendo responsável por conflitos e guerras; é o "inimigo invisível”. Como na fala inicial do presidente, o futuro não carrega melhoras, mas uma nova Guerra Fria - dessa vez, incitada por simulações, códigos de computadores e próteses cibernéticas. A expectativa é apenas uma variação da experiência.

Porém, tal trans-humanismo não opera apenas no saber científico: a ficção parece ter igual força na narrativa de Black Ops 3, principalmente nas temáticas também trabalhadas pelo escritor estadunidense Philip K. Dick (1928-1982). Autor da frase "a realidade é aquilo que, mesmo quando paramos de acreditar, continua existindo" "11, ele explorou veementemente o conceito de realidade. Em suas obras Do androids dream of electric sheep? (1968) ${ }^{12}$ e We can remember it wholesome (1966) $)^{13}$, temos androides ("replicantes") que acreditam piamente em serem humanos por possuírem memórias implantadas e que até, no segundo caso, vendem lembranças de lugares exóticos para pessoas que não possuem condições de conhecê-los diretamente.

— Uma memória extrafactual é mesmo assim tão convincente? - perguntou Quail.

- Mais do que real, senhor. Se tivesse mesmo ido a Marte como agente da Interplan, teria esquecido muita coisa. Nossa análise dos sistemas de memória verdadeira, lembrança autêntica de acontecimentos importantes na vida da pessoa, mostra que uma variedade de detalhes se apaga muito rapidamente. Para sempre. Parte do pacote que lhe oferecemos é uma implantação de memória tão profundo que nada é esquecido [...] A memória real, com todas as suas incertezas, omissões e lacunas, para não dizer distorções, essa sim é a segunda opção (DICK, 2012, p. 14).

O futuro presente de Black Ops 3 reúne um espaço de experiência tanto científico quanto ficcional, mas ambos históricos ou "historicizáveis". Sua expectativa preconiza apenas variações de um passado presente, de guerras extraoficiais, mentiras e constantes verdades manipuladas, ou seja, "realidades simuladas". É um porvir que escalona a aceitação do que é

\footnotetext{
${ }^{11}$ Ensaio original de 1978, disponível em: <http://deoxy.org/pkd_how2build.htm>. Acesso em: 26 dez. 2016.

12 Tradução mais recente: Androides sonham com ovelhas elétricas? (Editora Aleph, 2014).

${ }^{13}$ Tradução mais recente: Realidades Adaptadas (Editora Aleph, 2012).
} 
real no descontrole da aplicação tecnológica; que, em sua raiz, é apenas a continuidade do presente, isto é, uma espécie de presentismo, como trabalhado por Hartog (2014, p. 245):

[...] esse futuro não é mais promessa ou 'princípio de esperança', mas ameaça. Tal é a reviravolta. Uma ameaça que lançamos e da qual devemos nos reconhecer, hoje na falta do ontem já, como os responsáveis [...] Esse futuro não é mais um horizonte luminoso rumo ao qual caminhamos, mas uma linha de sombra que colocamos em movimento em nossa direção enquanto parecemos patinar no campo do presente e ruminar um passado que não passa.

Conseguimos imaginar um mundo sem guerras? Ademais, conseguimos formular um projeto social que garanta esse mundo? Se as máquinas se proliferaram a ponto de estarem em todos os aspectos de nossa vida cotidiana, nosso medo também se proliferou: podemos não só morrer pelas mãos de uma tecnologia advinda de uma ganância descontrolada como também estarmos, neste exato momento, sendo observados. Isso não é um medo descabido no contexto em que estamos, principalmente quando pode ser praticado pelo próprio Estado. No jogo, Sebastian Krueger se encarrega de tal temática ao afirmar:

Sempre foi pelo controle. Você tem ideia do quanto à tecnologia mudou cada aspecto de nossa vida cotidiana? Você não pode sequer começar a imaginar o... incontável número de pesquisas e desenvolvimentos que tivemos que monitorar para o melhoramento e segurança da Raça Humana. Cada gimmick ou gadget que era incorporado pelo público, cada um apresentava novas maneiras de nossos inimigos comprometerem nossa segurança. Sociedade não acontece, simplesmente. As pessoas precisam ser protegidas. Se a única maneira de prevenir futuros ataques seja monitorar os pensamentos e desejos da população, então a escolha é óbvia. Nós precisávamos saber quem são nossos inimigos e o que estão planejando! É assim que se salva vidas!" (Missão Life) $^{14}$.

Já em seu contexto, as ações da NSA, a Agência Nacional de Segurança dos Estados Unidos (EUA), evidenciam qual experiência está sendo referenciada na obra. Em 2013, o então funcionário da agência, John Snowden, revelou ao país que seus cidadãos estavam sendo monitorados constantemente por câmeras, microfones e diversos outros meios que violavam diretamente a privacidade de cada pessoa. Em entrevista ao jornal The Guardian, no mesmo ano, ele explicita seus medos:

\footnotetext{
${ }^{14}$ No original: "It was always about control. Do you have any idea just how much technology has changed every single aspect of our daily lives? You can't begin to imagine the... countless strains of research and development we had to watch over for the betterment and safety of the Human Race. Every new gimmick and gadget that was embraced by the public, each one presented new ways for our enemies to compromise our security. Society doesn't just happen. The people need to be protected. If the only way to prevent future attacks is to monitor the thoughts and desires of the population, then the coice is obvious. We need to know who our enemies are and what they are planning! That is how you save lives!"
} 
E nos meses pela frente, nos anos pela frente, só vai piorar, até que, eventualmente, haverá um momento em que as políticas irão mudar, porque a única coisa que restringe a atividade do Estado de Vigilância são as medidas políticas. Até mesmo nossos acordos com outros governos soberanos, nós consideramos isso como uma estipulação política ao invés de estipulação legal. E, devido a isso, um novo líder será eleito, eles encontrarão o interruptor, dirão que "Em razão da crise, em razão dos perigos que enfrentamos no mundo, alguma ameaça nova e imprevisível, nós precisamos de mais autoridade, nós precisamos de mais poder". E não haverá nada que as pessoas poderão fazer nesse ponto para se oporem. E será a tirania carcerária ${ }^{15}$.

Entre as experiências traumáticas da sociedade ocidental e as expectativas pessimistas do nosso entretenimento, de nossos historiadores e cientistas, temos o presente não só da narrativa de Black Ops 3 como também o nosso, isto é, "um novo presente, um único presente, o da guerra contra o terrorismo" (HARTOG, 2014, p. 136). O da nossa aparente incapacidade de imaginar um futuro radicalmente diferente e melhor: em 50 anos, ainda estaríamos em “Guerra ao Terror”. Utópicos são os sonhadores, os literatos, os carregados de ficção que estão "fora da realidade" e que, por isso, não podem produzir alternativas viáveis:

Num contexto moral e intelectual relativamente triste, no qual se apaga a presença de pensamentos fortes e figuras maiores, a criatividade se torna mais rara. Os desastres, a guerra, a inelutabilidade do desemprego constroem céus imóveis. São tachadas de utópicos, de arcaicos aqueles que ingenuamente se perguntam ainda "como sair dessa". O presente não é sequer sombrio, está na palidez lívida de espaços que não existem, e o indivíduo parece desarmado, inapto a pensar de outra maneira, a se "desprender", segundo a expressão de Michel Foucault largamente utilizada ainda há quatro ou cinco anos e que parece agora fora de propósito (FARGE, 2011, p. 106).

\section{CONSIDERAÇÕES FINAIS}

Como afirmado por During (2013, p. 224), “o futuro é uma força insinuante que não cessa de desfazer a evidência do presente". Hipervalorização de presente... de quem? Para quem? Em outras palavras, mesmo que estejamos inseridos em uma sociedade capitalista ocidental em contexto informatizado e globalizado, afirmar ela como um todo, estando envolvida em uma contemplação hipertrofiada do presente, significa ignorar os vários aspectos que a constituem enquanto tal. Seria ingenuidade não afirmarmos que a hipótese de Hartog $(2013,2014)$ acerca de um possível "presentismo", enquanto um regime de

\footnotetext{
${ }^{15}$ A entrevista pode ser assistida no link: <https://www.youtube.com/watch?v=0hLjuVyIIrs >. Acesso em: 30 jun. 2016. A versão transcrita pode ser lida em: <https://mic.com/articles/47355/edward-snowden-interviewtranscript-full-text-read-the-guardian-s-entire-interview-with-the-man-who-leaked-prism\#.qgg0Uqb6Y >. Acesso em: 30 jun. 2016.
} 
historicidade, não tenha influenciado nossas ideias, mesmo que não tenhamos trabalhado nos termos do autor.

Call of Duty Black Ops 3 é uma produção estadunidense. Ela respeita e/ou relaciona-se com a ordem temporal de seu contexto cultural, tanto temporal quanto espacial. Relativamente, a hipótese do presentismo advém de uma série de experiências europeias. Assim como é um desafio “pensar as possibilidades e os limites da 'transposição' de diagnósticos europeus para a realidade brasileira" (DA MATA et al., 2012, p. 10), também é transplantarmos a narrativa de um jogo para uma cultura que também poderia abarcar o Brasil, afinal, mesmo latinos, ainda somos considerados ocidentais. Entretanto, é exatamente nas críticas a tal hipótese generalizante que poderemos suscitar algumas possibilidades. De acordo com Zoltan Simon,

\begin{abstract}
Ainda assim, esse presentismo autoimposto permanece unicamente apenas um lado da moeda, já que concerne ao projeto utópico-ideológico. O outro lado é a proliferação da imaginação tecnológica e de visões futuras simultaneamente lançadas quando a imaginação ideológico-política ocidental foi declarada como falida. Você pode ter em mente os programas espaciais do mesmo período ou o entusiasmo sci-fi de 1950 e 1960, tanto no cinema quanto na literatura, a qual foi inspirada por visões tecnológicas contemporâneas refletidas na base de pesquisas sobre inteligência artificial como campo científico, separando-se da cibernética em 1956. Atualmente, essa visão tecnológica é mais onipresente que jamais foi. Você não consegue escapar assim que vai ao cinema ou para a internet. Assim como todo o segundo blockbuster ou como o último romance de DeLilo, histórias de revistas e debates públicos agora habitualmente tratam de questões como trans-humanismo, bioengenharia, nanotecnologia, criogenia, aperfeiçoamento humano, inteligência artificial, singularidade tecnológica, planos para colonizar Marte, e assim por diante ${ }^{16}$.
\end{abstract}

Embora o autor pareça não levar em conta que essas produções de ficção científica podem existir em um presente sem perspectivas, mesmo se passando no futuro (como tentamos demonstrar com a narrativa de Black Ops 3), o autor abre a possibilidade de pensarmos a multiplicidade de maneiras de organizar, pensar e significar o tempo. Se, em termos de Koselleck (2014), a sociedade possui estratos temporais múltiplos ${ }^{17}$, não seria descabido pensar que podemos produzir o pessimismo em âmbitos diversos. A cultura da mídia é exatamente um desses âmbitos. Ela mesma é atravessada por maneiras distintas de projetar o futuro, pode muito bem ser mapeada em diferentes estilos de narrativas e

16 Tradução nossa. Texto completo em: <https://jhiblog.org/2016/05/02/we-have-never-been-presentist-onregimes-of-historicity/>. Acesso em: 30 jun. 2016.

17 "Tentarei em seguida compreender os resultados históricos por meio de uma estratificação temporal que pretende solapar a oposição entre o linear e o circular. Os tempos históricos consistem em vários estratos que remetem uns aos outros, mas que não dependem completamente uns dos outros" (KOSELLECK, 2014, p. 1920). 
produções. Na presente reflexão, buscamos demonstrar que, na perspectiva da interação entre ser humano e máquina, em estilo ficção científica, podemos observar um pessimismo latente. Em outras palavras, podemos projetar um futuro melhor para as relações de gênero, para os rumos da política e até para o time esportivo que torcemos, enquanto articulamos outro pior com relação às tecnologias como próteses e inteligências artificiais. Esse é o aspecto significador da narrativa, que organiza, dá sentido e cria uma realidade: não significa negar que não há o real, mas que é possível a existência de vários reais porque nós, seres humanos, somos vários. Essa é a força naturalizante que a mídia, e, consequentemente, os jogos eletrônicos possuem sobre aqueles que atua.

Participamos dos jogos constituindo com eles relações diversas; construímos e somos construídos por tais relações. Somos convencidos, por meio das histórias, narrativas e personagens dos jogos, dos prazeres e dos riscos de saltar, pular, correr, nadar, atirar, morrer e matar. Com base nesses processos de convencimento, passamos a participar de comunidades de jogadores. Envolvemo-nos tanto com as narrativas e as personagens que chegamos a suar, a ter taquicardia, ou simplesmente ficamos contentes ou frustrados. Nesses momentos, será que sabemos onde estamos? (dentro da máquina?; fora da máquina?) Sabemos o que somos? ("eu" jogador?; "eu" personagem?; "eu" máquina?). Por que, em alguns casos, demoramos a nos localizar no tempo e no espaço? Por que sonhamos com situações dos jogos, como fazemos com qualquer acontecimento cotidiano (MENDES, 2006, p. 16-17).

A virtualidade do cenário construído pelos jogos eletrônicos não faz com que tenham capacidade "menor" de falar (uma) verdade, de servir como objeto para melhor entendimento de nossa sociedade e como auxílio para projetos de mudança. "Ao observarmos de forma panorâmica a evolução das técnicas de registro, difusão e recepção dos audiovisuais, percebemos que elas dependem dos padrões culturais de percepção visual e sonora, ao mesmo tempo em que os transformam" (HAGEMEYER, 2012, p. 105). A primazia pelo virtual e pela simulação, em nossos tempos, representa novos parâmetros pelos quais a sociedade age no cotidiano das ideias e significados, e depende de nós, historiadores, pensarmos em novas maneiras de abarcamos e analisarmos tais mundos virtuais, tanto para que possamos dialogar com a juventude progressivamente mais midiatizada e informatizada quanto para repensarmos a importância da História em tal contexto, visto que "o virtual se configura como um acontecimento transformador das práticas de produção de sentido e de percepção e apropriação do mundo" (CABRA, 2011, p. 88. Tradução nossa) ${ }^{18}$.

\footnotetext{
${ }^{18}$ No original: "lo virtual se configura como un acontecimiento transformador de las prácticas de producción de sentido y de percepción y apropiación del mundo".
} 


\section{REFERÊNCIAS}

ANKERSMIT, Frank. Truth in History. Narrative, Ohio, v. 18, n. 1, p. 29-50, jan. 2010.

BUTLER, Samuel. Erewhon or Over the Range. London: Trübner \& Co., 1872.

CABRA, Nina Alejandra. Entre el fantasma, el avatar y otras mutacioness de la imagens. Nomadas, n. 35, p. 81-97, out. 2011.

DA MATA, Sérgio et al. Tempo presente \& usos do passado. Rio de Janeiro: Editora FGV, 2012.

DICK, Philip K. Realidades Adaptadas. São Paulo: ALEPH, 2012

DURING, Elie. O que é retrofuturismo? - Introdução aos futuros virtuais. In: NOVAES, Adauto (Org.). O futuro não é mais o que era. São Paulo: Edições Sesc SP, 2013. p. 209-323.

FARGE, Arlette. Lugares para a história. Belo Horizonte: Autêntica Editora, 2011.

GIGERENZER, Gerd; GOLDSTEIN, Daniel C. Mind as a Computer: Birth of a Metaphor. Creativity Research Journal, Chicago, v. 9, n. 2-3, p. 131-144, 1996.

HAGEMEYER, Rafael Rosa. História \& Audiovisual. Belo Horizonte: Editora Autêntica, 2012.

HARTOG, François. Experiências do Tempo: da história universal à história global. Histórias, histórias, Brasília, v. 1, n. 1, p. 164-179, 2013.

Regimes de Historicidade: presentismo e experiências do tempo. Belo Horizonte: Editora Autêntica, 2014.

HEIJDEN, A. H. C. van der; STEBBINS, Sarah. The information-processing approach. Psychological Research, Berlim, p. 197-206, 1990.

KELLNER, Douglas. A cultura da mídia. São Paulo: EDUSC, 2001.

KOSELLECK, Reinhart. Estratos do Tempo: estudos sobre história. Rio de Janeiro: Contraponto, 2014.

Futuro Passado: contribuição à semântica dos tempos históricos. Rio de Janeiro: Contraponto: Ed. PUC-Rio, 2006.

MENDES, Claudio Lúcio. Jogos eletrônicos: diversão, poder e subjetivação. Campinas, SP: Papirus, 2006.

PEGORARO, Olinto A. Sentidos da história: eterno retorno, destino, acaso, desígnio inteligente, progresso sem fim. Petrópolis: Vozes, 2011.

SIMON, Zoltan Boldizsár. We Have Never Been Presentist: On Regimes of Historicity. Disponível em: <https://jhiblog.org/2016/05/02/we-have-never-been-presentist-on-regimesof-historicity/>. Acesso em: 30 jun. 2016. 
XAVIER, Guilherme. A condição eletrolúdica: cultura visual nos jogos eletrônicos. Rio de Janeiro: Novas Ideias, 2010.

WHITE, Hayden. The Content of the form: narrative discourse and historical representation. Baltimore: Johns Hopkins Paperbacks edition, 1990.

ARTIGO ENVIADO EM: 03/08/2016 ARTIGO ACEITO PARA PUBLICAÇÃO EM: 10/01/2017 